\title{
Impairment Evaluation in Pain Management Physician, or Attorney in White Coat?
}

\author{
Laxmaiah Manchikanti, MD
}

Impairment and disability evaluations have become a growth industry in the United States. Impairment evaluation is sometimes termed independent medical evaluation, or IME. So-called independent medical experts are hired guns to provide opposite opinions, similar to attorneys in this case. IME is the practice of medicine on one hand. On the other hand, it is the practice of law in white coats.

Impairment is defined as the loss of a physiologic function or of an anatomic structure. Disability, however, is defined as an inability or altered ability to successfully accomplish a given task. For successful implementation of various disability systems, the essential medical/legal interface can be successfully achieved only if the physician has atleast a minimum level of understanding of the legal system, and the attorney has an adequate understanding of the medical facts and the limits of medical science.
Many physicians approach impairment ratings and disability evaluations by extrapolating from the knowledge and experience gained in their specialties. However, there are numerous fundamental differences between the standard medical evaluation and impairment/disability evaluation.

Important aspects of impairment evaluation include medical evaluation, analysis of findings, and comparison of the results. In impairment evaluation, it is crucial to establish causal relationship and decide on maximum medical improvement, apart from providing the impairment rating. This review will discuss various aspects of impairment evaluation.

Keywords: Impairment evaluation, interventional pain management, disability, impairment rating

\section{"Every profession is a conspiracy against the laity."}

\section{— George Bernard Shaw}

The observation of George Bernard Shaw has never been so fitting until recently. It perfectly describes the ultra rapid growth industry of independent medical evaluation (IME), even though public wisdom never embraced that iconoclastic view in reference to medicine or law. The enterprise of IME or disability analysis expands beyond the practice of medicine, Hippocratic oath, and patient advocacy, not only interfacing, but also entering into the legal arena. Thus, a physician performing an IME transforms into an attorney in a white coat.

From Pain Management Center of Paducah, Paducah, KY. Dr. Manchikanti is medical director of Pain Management Center of Paducah. Address correspondence: Laxmaiah Manchikanti, MD, 2831 Lone Oak Road, Paducah, KY 42003
Worker's compensation claims, civil suits, and medical, and legal problems are facts of life for a substantial number of interventional pain specialists. Impairment, and disability are facts of life for a substantial number of Americans, specifically those who suffer from chronic pain. Pain and disability are both complex phenomenons that are difficult to define, and pose a formidable task in their assessment. "Pain" as John Bonica, Father of Pain Medicine, observed in 1974, "is the most pressing issue of modern times." In spite of the best efforts of the public, providers, and the government, pain continues to be an epidemic $(1,2)$. The concept of chronic pain is beset with controversy starting with its very definition. Two problematic terms in today's pain medicine are "chronic pain" - also known as persistent pain - versus a second category known as "chronic pain syndrome," which is a separate and distinct condition $(4,5)$. Bonica (3) defines chronic pain as, "Pain which persists a month beyond the usual course of an acute disease or a reasonable time for any injury to heal that is associated with chronic pathological processes that causes a continuous pain or pain at intervals for months or years". In the United States, chronic pain costs an estimated \$120 
billion per year in treatment, lost revenues, disability, and wages. Some frightening estimates show that the annual total cost for back pain itself -- including disability and litigation is more than $\$ 100$ billion (6).

Pain, in addition to various other problems, also leads to varying degrees of alternation in function. This could vary from a minor inconvenience --, to a significant disability, such as the inability to work or participate in enjoyable activities. Thus, disability, similar to chronic pain, is a complex problem. Terms such as "impairment" and "disability" are used in different settings with different meanings. In addition, the different systems of disability define impairment and disability in their own terminologies in different contexts. While impairment and disability may ensue secondary to multiple external forces and causes, the process of life and aging itself guarantees that if we live long enough, impairment and disability of some sort will occur. Impairment and disability have always been unwanted human conditions. This has lead to either punishment, such as extermination in Nazi Germany in concentration camps of disabled and impaired persons or occasionally the subject of miraculous recoveries, such as Jesus healing the lame and the blind.

However, what is new is that in modern times, impairment and disability have been accorded legal status. Impairment and disability are major economic and social issues in developed countries. Consequently, the definitions of impairment and disability expand and contract more along political and ideological lines than according to any clear physical determinations. And the United States is no exception.

\section{HISTORICAL CONSIDERATIONS}

The development of disability as a legal entity dated back to the English Poor Law of 1601 (7). In 1898, when addressing work disability, the government of Germany decided that disability was a function of lost earning capacity and job opportunities and not, as narrowly interpreted in the English Poor Law, a categorical incapacity to work (7). In contrast, in the United States, the first legal recognition of disability developed out of the tremendous industrial expansion that started after the Civil War and extended into the early $20^{\text {th }}$ century (7). The spectacular catastrophes of West Virginia in 1907 with 362 deaths of minors and the 1911 fire in New York with 164 deaths lead to growth of social concern for a remedy to the poverty caused by workrelated injuries and fatalities $(7,8)$. Each state in the United States passed worker's compensation statutes, beginning with New York in 1910 and ending with Mississippi being the final state to enact such a law in 1949. In 1956 the social security law was amended to provide disability benefits to individuals between the ages of 50 and 65 who, because of disability, were unable to work according to the above definition (9). Since then, the law was amended on multiple occasions to include monthly benefits to dependents of disabled workers, to remove the limitation of eligibility at 50. Finally, in 1965, the definition of disability changed to one which remains the same after three decades (9). AMA Guides to the Evaluation of Permanent Impairment began to take form during the 1950s to improve estimates of the severity of human impairments, basing them on accepted medical standards by the American Medical Association. However, the first edition of the Guides were not published until 1971.

\section{DEFINITIONS}

The World Health Organization (WHO) has defined impairment as "any loss or abnormality of psychological, physiological, or anatomical structure or function" (10). Thus, impairment is the loss of a physiologic function or an anatomic structure. Intellectual impairment involves diminished or lost cognitive function. AMA Guides to the Evaluation of Permanent Impairment defines impairment as, "a deviation from normal in a body part or organ system and its functioning" (4). Impairment is considered as, "an alteration of an individual's health status" (4). Consequently, impairment is a medical issue and is assessed by medical means. According to the AMA Guides, permanent impairment is defined as, "one that has become static or stabilized during a period of time sufficient to allow optimal tissue repair, and one that is unlikely to change in spite of further medical or surgical therapy". A permanent impairment is considered to be unlikely to change substantially and by more than $3 \%$ in the next year with or without medical treatment (4). In addition, the AMA Guides describe impairment as conditions that interfere with an individual's "activities of daily living," including self-care and personal hygiene; eating and preparing food; speaking, and writing; maintaining one's posture, standing, and sitting; caring for the home and personal finances; walking, traveling, and moving about; recreational and social activities; and work activities.

WHO defines a disability as, "any restriction or lack (resulting from an impairment) of ability to perform an activity in the manner or within the range considered normal for a human being" (10). The AMA Guides define disability as "inability or altered ability to successfully accomplish a 
Table 1: Characteristics and differences between impairment and disability

\begin{tabular}{|c|c|}
\hline Impairment & Disability \\
\hline An alteration in individual's health status & An alteration in individual's capacity to function \\
\hline $\begin{array}{l}\text { A deviation from normal in a body part or } \\
\text { organ system, and its functioning }\end{array}$ & $\begin{array}{l}\text { An individual's inability to accomplish an activity or } \\
\text { task }\end{array}$ \\
\hline $\begin{array}{l}\text { Any loss or abnormality of psychological, } \\
\text { physiological, or anatomical structure or } \\
\text { function }\end{array}$ & $\begin{array}{l}\text { Any restriction or lack [resulting from an impairment] } \\
\text { or inability to perform an activity in the manner or } \\
\text { within the range considered normal for a human being }\end{array}$ \\
\hline $\begin{array}{l}\text { Condition or conditions that interfere with } \\
\text { an individual's activities of daily living }\end{array}$ & $\begin{array}{l}\text { An alternation of an individual's capacity to meet } \\
\text { personal, social, or occupational demands, or } \\
\text { statutory or regulatory requirements because of an } \\
\text { impairment }\end{array}$ \\
\hline Medical issue & Administrative issue \\
\hline What is medically wrong & $\begin{array}{l}\text { The gap between what a person can do and what the } \\
\text { person needs or wants to do }\end{array}$ \\
\hline
\end{tabular}

given task" (4). Thus, disability arises out of an individual's inability to perform a task successfully because of insufficiency in one or more areas of functional capability: physical function, mental function, agility, dexterity, coordination, strength, endurance, knowledge, skill, intellectual ability, or experience. According to the AMA Guides:, "Disability is a decrease in, or the loss or absence of, the capacity of an individual to meet personal, social, or occupational demands, or to meet statutory or regulatory requirements." Disability "is not necessarily related to any health impairment or medical condition, although a medical condition or impairment may cause or contribute to disability." Thus, conceptually disability is "the gap between what a person can do and what the person needs or wants to do" (4). Similar to impairment, disability may also be temporary or permanent depending on the ability to treat the medical condition. Further, disability of varying degrees is described partial or complete. Thus, an impaired individual "is not necessarily disabled" (4). Permanent disability "occurs when the limiting loss or absence of capacity becomes static or well-stabilized and is not likely to change in spite of continuing use of medical rehabilitative measures" (4). A permanent disability is considered to be unlikely to change substantially and by more than $3 \%$ in the next year with or without medical treatment (4). Evaluation or rating of disability is a nonmedical assessment of the degree to which an individual does or does not have the capacity to meet personal, social, occupational, or other demands, or to meet statutory or regulatory requirements (4). Table 1 identifies the differences between impairment and disability.

Finally, handicap is another word related to but different from the concepts of disability and impairment. Under federal law, an individual is handicapped if he or she has an impairment that substantially limits one or more of life's activities, has a record of such impairment, or is regarded as having such an impairment. However, this definition is so broad that almost any person may be considered to be handicapped under it. WHO defines handicap as "a disadvantage for a given individual, resulting from an impairment or a disability that limits or prevents the fulfillment of a role that's normal (depending on age, sex, and social and cultural factors) for that individual" (10).

The Americans with Disabilities Act (ADA) is intended to help organizations to employ qualified individuals with "disabilities." These include various issues regarding per- 
formance capability, acceptability of risks to oneself or others, the need for accommodation, and type of accommodation that may be warranted. It is important to recognize that none of these are a medical issue. The definition of impairment or disability under ADA is somewhat different than under the Guides to the Evaluation of Permanent Impairment. As per ADA, disability means "a physical or mental impairment that substantially limits one or more of the major life activities of the individual; or a record of such an impairment; or being regarded as having such an impairment. Essential functions of the job, major life activities, substantial limitation, and accommodation are the important words used under this act. ADA use of the term "disability" and its use of the concept is similar to the concept of "impairment" used in the Guides. However, it is important to note that the ADA identification of an individual with a "disability" does not depend on the results of the medical evaluation. An individual may be identified as having a disability if there is a record of an impairment that substantially limited one or more major life activities; or, of greater concern, the individual is regarded as having a disability. Finally, "accomodation" is not a medical matter. Accommodation is the result of an employer's decision regarding modifications of a job or a work place "that are reasonable with respect to the employer's cost and the degree of hardship imposed." The physician may help the employer explore the need for accommodation or help the employer to understand the relationship between a medical impairment and individual capabilities. However, it is not appropriate for the physician to recommend a specific accommodation.

\section{CONCEPTUAL BASIS OF IMPAIRMENT/ DISABILITY}

Evaluation of impairment, and disability have become a growth industry in the United States. Impairment evaluation, or IME, is an acronym for Independent Medical Evaluation. However, IME is also known as the Impartial Medical Evaluation, Insurance Medical Evaluation, and Interested Party Medical Evaluation. In some areas, IMEs may be known as Agreed Medical Examinations, Binding Medical Examinations, or Neutral Medical Examinations. IMEs may be requested by attorneys on either side, employers, rehabilitation specialists, judges, commissioners, and other participants. These hired medical experts are also referred to as "dueling doctors" to give opposite opinions, similar to attorneys in the case. Hence, IME appears to be a misnomer. As per Webster's Dictionary, independent is defined as, "free from authority, control, or influence of oth- ers, self-governing, or causally unconnected." Similarly, impartial is defined as, "without prejudgment, an impartial mind not favoring one side more than the other." Hence, IME and these definitions are a mismatch, as they are neither independent or impartial, nor purely medical evaluations.

Melvin and Nagi (11) in 1970 provided a conceptual basis of disability, which included pathology, impairment, functional limitation, and disability.

\section{Pathology}

Pathology is either altered anatomy and/or altered physiology. Thus, pathology not only includes the initial injury to the body from trauma, metabolic disorders, infection, or any other type of etiology, but also the body's response to such an injury. In addition, it also includes any aggravation of a previously existing problem.

\section{Impairment}

An impairment is defined as an anatomical, physiological, or psychological abnormality or loss $(12,13)$. As such, impairments are divided into temporary and permanent. Temporary impairment is present during active pathology, which may become permanent impairment, continuing even after the active pathology is adequately treated and resolved. Anatomical impairments include decreased range of motion, deformities, loss of an organ, and contractures, whereas physiological impairments include muscle weakness, alternation in reflexes, decreased strength, loss of sensation, abnormal electromyographic studies, abnormal blood chemistry, and decreased pulmonary function, etc. In contrast, psychological impairment includes changes in cognition and memory, depression, and generalized anxiety disorder.

\section{Functional Limitation}

A functional limitation is defined as "a restriction or the lack of the ability to perform an activity of function in the manner within the range considered normal for that person." Various types of functional limitations include gait disturbances, lifting limitations, inability to perform stressful activities, or inability to function safely in a community in an individual with cognitive and effective changes. Essentially, functional limitations are manifestations of impairment that are translated in terms of function. 


\section{Disability}

The inability of an individual to perform his or her usual activities and to assume their usual obligations is viewed as disability. Thus, disability is "task specific." Permanent disability is presumed to be present if an individual's actual or presumed ability to engage in gainful activities is reduced or absent, due to an impairment, which in turn may or may not be combined with other factors $(13,14)$. Disability is generally viewed as a condition in a given individual that results from impairment, and the functional limitations that essentially prevent fulfillment or a role that is normal for that individual. Various conditions limit the fulfilling of roles in life, such as a worker, student, or caregiver. Hence, disability is not only task specific but also role specific.

\section{DISABILITY SYSTEMS IN THE UNITEDSTATES}

Numerous disability systems are available in the United States, including state worker's compensation systems, the Federal Employee's Compensation Program, Longshore and Harbor Worker's Compensation Program, Black Lung Program, Veterans and Military Disability, Railroad Workers and Seamen Compensation System, Social Security Disability Systems, and Private Disability Systems (15). As one can imagine, the definition of impairment and disability, though similar, is variable among various systems. While most state workers' compensation systems follow the system developed by the American Medical Association and the Guides; some have developed their own guides and interpretations. In contrast, social security disability systems are radically different from workers' compensation or private disability systems.

The Social Security Administration (SSA) administers social security disability systems in two formats: social security disability insurance (SSDI) program and the supplementary security income (SSI) program, Title 16. SSDI provides coverage for cash benefits for those disabled workers and their dependents who have contributed to the social security trust fund through the Federal Insurance Contribution Act (FICA) tax on their earnings. SSI provides for a minimum income level for the needy, aged, blind, and disabled. Social security defines disability as, "the inability to engage in any substantial gainful activity by reason of any medically determinable physical or mental impairment which can be expected to result in death or has lasted or can be expected to last for a continuous period of not less than 12 months." To meet this definition, an individual's impairment or combination of impairments "(are) to be of such severity that he/she is not only unable to do his/her previous work, but cannot, considering his age, education, and work experience, engage in any other kind of substantial gainful work which exists in the national economy."

The term substantial gainful activity (SGA) means any work activity that involves significant and productive physical or mental activities and is performed or intended for pay or profit - currently up to $\$ 500$ per month for disabled persons and $\$ 850$ per month for the blind (15).

\section{MEDICAL AND LEGAL ISSUES}

For successful implementation of disability systems, the medical legal interface is essential. This can be successfully achieved if the physician has atleast a minimum level of understanding of the legal system, and the attorney has an adequate understanding of the medical facts and the limits of medical science. Understandably, some physicians fear interaction with the legal world, while others are not cautious enough. Those paranoid, overly wary physicians who see a potential lawsuit at every corner refuse to give a written opinion or hesitate to give an honest opinion. Thus, these physicians are not practicing medicine. However, the physicians who believe they can do whatever they want based on their experience or who are not serving the profession. Thus, both physicians are useless to the patient and the legal system itself. The physicians performing independent medical evaluations - too often believe that the only entity to which they are responsible is the organization which is paying them and that they are insulated from malpractice suits. However, physicians in the evaluation of impairment and disability, like any other physician, commit malpractice if their treatment or actions do not follow a reasonable standard of care. It is crucial to note that workers' compensation is the exclusive remedy only between the employee and the employer and its agents/other employees, but not the third party, such as a physician.

\section{DISABILITY EVALUATION}

While performing disability or impairment evaluations is another part of physicians' work, most physicians are not trained in this aspect. Consequently, many physicians approach impairment and disability evaluations by extrapolating from the knowledge and experience gained in their own specialties, or stay away from them altogether. There are fundamental differences between the standard medical examination and a disability examination. Medical evalua- 
tions have long served dual functions, providing medical diagnoses and directing the physician towards effective treatment. While medical evaluations work extremely well in cases of acute illness with a clear cure, in chronic illness, evaluation in providing diagnosis by a treating physician can create conflicts. Sullivan and Loeser (16) examined the relationship between a pain clinic and a workers' compensation program and concluded that: the roles of treating and rating physicians are not compatible in chronic pain cases; and the measurement of disability due to pain through physician ratings is confusing and probably invalid. However, a treating physician is considered to be the best person to provide a disability rating. One of the most compelling reasons offered for a single physician undertaking both the treatment and disability evaluations of a given patient is that the diagnostic information obtained from the patient can be applied toward disability evaluation. In addition, it is contended that patients tend to reveal information more readily to their treating physician than to a physician who they see solely for disability rating (16). However, Sullivan and Loeser (16) contend that this is the first sign of trouble, because a treating physician acting as a disability evaluator is not only borrowing knowledge obtained through his or her role as a treating physician but also is borrowing the patient's trust as well. Essentially, patient evaluations for the purposes of treating and disability evaluations create fundamentally different relationships. A treating physician assumes the role of provider of medical diagnosis, selecting effective treatment for the patient's pain and attempting to reduce suffering. However, a disability evaluating physician acts as an agent for the payor to assign impairment rating, in spite of providing routine disclaimers (Table 2). However, there are also similarities between a disability evaluation and a standard medical examination, including the patient's history, physical examination, and the ordering of appropriate laboratory tests.

In general, medical disability evaluations are carried out utilizing AMA Guides to the Evaluation of Permanent Impairment, the latest available edition. In fact, the use of the AMA Guides to the Evaluation of Permanent Impairment, in worker's compensation cases, is spreading rapidly in both the medical and legal communities in the United States (4). This also applies to the other areas of litigation such as motor vehicle injuries, falls, and other liability cases. At the time of the printing of the fourth edition of the AMA Guides in 1993, 38 states and two territories required the use of AMA Guides in some form. In addition, Canada also has begun to rely on the AMA Guides, along with various other countries with similar types of workers' com- pensation systems. In addition to the state workers' compensation systems, the Federal Employees Compensation Act and Longshore and Harper Worker's Compensation Act require the use of the AMA Guides. While an Arizona court questioned whether the AMA Guides represented the true measure of the impairment and concluded that the evidence is unclear, no court has ruled directly on the validity of the AMA Guides in its entirety, even though other courts have held that the AMA Guides are not to be followed blindly; are inapplicable to hearing loss cases and occupational diseases, such as contact dermitis; do not cover subjective complaints; do not cover pain; are of doubtful authority and are inconsistent with state workers' compensation statues (17-20). However, the Idaho Supreme Court found the AMA Guides could be utilized, even if the testifying physician has no opinion as to the proper rating (17-20). The drawbacks of AMA Guidelines include lack of scientific validity, of dependency on sound epidemiologic studies of large population groups, and of peer-reviewing. Hence, it is crucial to remember that impairment is simply an arbitrary number representing the percentage of the function of the body that may have been lost. How the impairment effects the individual in activities of daily living including return to work is a much more complicated issue of disability.

The role of the physician in impairment assessment includes clarification not only of physical issues but also behavioral, psychosocial, vocational, claims, and legal issues. Performance of impairment assessments requires specific skills in addition to clinical knowledge. The physician must have not only a strong clinical background but also an appreciation of the biomedical, mental, emotional, and vocational aspects of injury and illness. Unfortunately, the quality of impairment evaluations and evaluators varies widely. Though similar to that of treatment physicians, the quality is much more dependent on financial incentives, ethical obligations, and the evaluators' perceptions of the treating physicians and patients. It is often stated that assessments are mainly requested due to lack of medical information or conflict on specific matters, especially regarding the cause of the condition and persons ability to work. In reality, though, most assessments are requested either to stop benefits to the person, to reduce the impairment, or to stop and/or disallow the treatment. While the impairment assessment process must be precise and detailed, and assure that conclusions are valid, reliable, defensible, and useful, in actuality, most assessments performed by certain physicians, groups of physicians trained by certain organizations, and physicians who are consistently favored by either insurers or attorneys are too simi- 
Table 2. Differences between an independent disability evaluation and a medical evaluation

\begin{tabular}{clll}
\hline & & Medical Evaluation & Independent Disability Evaluation \\
\hline 1. & Referral source & Physicians, patients, self, family & Insurers, attorneys, employers, judges \\
2. & Type of practice & Medical & Legal or medical/legal \\
3. & Opportunities for examination & Voluntary & At best agreed \\
4. & Goals & Diagnosis \& treatment & Disability assessment \\
5. & Work history & Somewhat important & Crucial \\
6. & Specific issues addressed & Medical issues & Causation, Impairment, restrictions \\
7. & Reliance on nonmedical personnel & Some & Significant \\
8. & Extrapolation regarding causation & Not required & Essential \\
9. & Type of relationship & Congenial & Adversial \\
10. & Trust in physician & Significant & Mostly distrust \\
11. & Trust in patient & Yes & None, suspicious \\
12. & Patient/physician relationship & Yes & No \\
13. & Payment responsibility & Patient & Referral source \\
14. & Physician role & Active & Passive \\
15. & Physician loyalty to & Patient & Insurer or payor \\
16. & Physician responsibility to & Patient & Payor \\
17. & Treatment recommendations & Yes & No \\
18. & Legal responsibilities & No & Yes \\
19. & Malpractice & Yes & Maybe \\
20. & End results & Do no harm & Don't leave any stone unturned \\
21. & Hippocratic oath & & \\
\hline
\end{tabular}

lar and reach the same conclusions in favor of the party requesting the evaluation, making the validity, reliability, usefulness, and defensibility of such evaluations questionable. In addition, impairment evaluations should be performed without bias to the financial relationship, which should be similar to the treatment provided if the same patient presented for medical evaluation. While many impairment evaluation specialists not practice a similar type of medicine or do not practice at all, many others ignore ethical obligations and the Hippocratic Oath, thus provid- ing extremely biased evaluations and opinions that are significantly different from those rendered in their medical practices. Arguments can also be made against treating physicians who may be too involved as a patient advocate. However, this does not compare to many independent evaluators, who start with the suspicion of guilt of the injured patient with no chance to prove either way; judgment has been made at the time of scheduling. The same may be said about evaluators who provide desired opinions for attorneys representing patients. 


\section{THE PROCESS OF EVALUATION}

Three important steps in evaluation of impairment include medical evaluation, analysis of findings, and the comparison of results to criteria in the AMA Guides (4).

\section{Medical Evaluation}

1. Narrative history with reference to onset and course, previous examination findings, treatment, and responses to treatment.

Results of most recent clinical evaluation.

- Assessment of current clinical status and tatement of plans for future treatment, rehabilitation, and re-evaluation.

- Diagnosis and clinical impressions.

- Estimated date of partial or whole recovery.

2. Analysis of findings

- Medical basis of maximum medical improvement.

- Impact of medical condition on life activities.

- The medical basis that the individual is or is not likely to suffer sudden, subtle, or other incapacitation as a result of a change in the condition (prognosis, pathophysiology).

- Medical basis that the individual is or is not likely to suffer injury or further impairment while trying to meet personal, social, and occupational demands (prognosis and physical risks).

- Medical opinion with regards to restrictions or accommodations, whether these are warranted or not warranted.

- An explanation of the expected outcome or value of any restrictions or accommodations, in addition to an explanation of whether or not the restrictions are because of risks to the patient or others.

\section{Comparison of Results to Criteria in the AMA Guides}

Specific clinical findings related to each impairment and how the findings related to AMA Guides criteria:

- Reference to the absence of or examiner's inability to obtain pertinent data.

- Explanation of impairment rating with direct reference to applicable criteria (protocol).

- Summary list of all impairments.

\section{Causal Relationship}

Causal relationship is a critical issue in work-related and liability cases, as the law generally does not provide compensation for a disease that is "an ordinary disease of life" or which is not "peculiar or characteristic of the employee's occupation or the incident". A work-related problem is defined as one that "arose out of and during the course of employment" (4). While determination of the causation is simple in some cases, it may well be an extremely complex and cumbersome phenomenon, particularly with pre-existing chronic conditions and environmental exposures. As per the Guides, "causation means that a physical, chemical, or biological factor contributed to the occurrence of a medical condition." To decide that a factor alleged to cause or contribute to the occurrence or worsening of a medical condition has actually done so, it is necessary to verify both of the following:

1. The alleged factor should have caused or contributed to worsening of the impairment, which is a medical determination.

2. The alleged factor did cause or contribute to worsening of the impairment, which is a non-medical determination.

\section{Aggravation}

Aggravation means "that a physical, chemical, or biological factor, which may or may not be work related, contributed to the worsening of a pre-existing medical condition or infirmity in such a way that the degree of permanent impairment increased by more than 3\%" (4).

Causation and aggravation must be verified in non-traumatic injuries, in contrast to traumatic injuries, which often can be related to an event that occurred at a particular time and place. The role of occupation or environmental factors in causing aggravating disorders of the various body systems is difficult to document. Documentation of "aggravation" or "causation" depends largely on the acquisition, review, and analysis of existing office and hospital records dating from the onset of the condition and including the initial evaluation for the condition; the results of tests or diagnostic procedures showing when and how the individual's health was affected by an alleged physical, chemical, or biological factors; and the results of occupational or environmental surveys, tests, or analyses.

Aggravation may involve both occupations and nonoccupational disorders: 
1. An occupational disorder may be aggravated by a supervening non-occupational disorder.

2. An occupational disorder may be aggravated by a supervening occupational condition arising out of or in the course of employment by the same employer.

3. An occupational disorder may be aggravated by a supervening industrial condition arising out of and in the course of employment by a different employer.

4. An occupational disorder may be aggravated by a pre-existing, non-occupational condition.

5. An occupational disorder may aggravate a preexisting, non-occupational condition.

It is the responsibility of an evaluating physician to establish a causal relationship that a certain condition arose out of or in the course of work duties to a reasonable degree of medical probability, which implies that it is more probable than not [i.e., there is more than 50\% probability; for example, 51 chances out of 100]. Possibility implies less than $50 \%$ likelihood. Work-related implies that a physician has arrived with an opinion based on available information, to a reasonable degree of medical probability or certainty, that the work activities caused the problem.

\section{Apportionment}

The physician also should deal with apportionment, defined by the Guides as "the degree to which each of various occupational or non-occupational factors may have caused or contributed to a particular impairment." For each alleged factor, two criteria must be met:

1. The alleged factor could have caused or contributed to the impairment which is a medical determination as defined in causation earlier.

2. In the case in question, the factor did cause or contribute to the impairment, which is usually a non-medical determination.

The physician's analysis and explanation of causation is significant. In cases where there are multiple factors involved and pre-existing conditions were present, it is necessary to apportion current impairment between the two conditions, which may be between two parities or work and non-work related conditions. This process depends largely on judgment, since the signs supporting apportionment still is in its infancy.

\section{Maximum Medical Improvement}

Maximum medical improvement, or MMI, indicates that further recovery and restoration of function can no longer be anticipated to a reasonable degree of medical probability (4). MMI that the condition has become static or wellstabilized, with or without medical treatment, and is not likely to remit despite medical treatment.

In arriving at the opinion of maximum medical improvement, consideration should be given to whether the current or proposed treatment will result in functional improvement and whether there has been appropriate interval for the condition stabilize. Maximum medical improvement is not to exclude a patient from further treatment, whether it's follow-up, maintenance or palliative care, and whether such treatment increases functional status or not. MMI does not preclude an alteration of the medical condition over time.

Thus, "MMI represents that point in time when, as the patient's medical condition has reached where the condition has stabilized or hit a plateau, no further material recovery or lasting improvement is expected or reasonably anticipated as a result of additional treatment based on reasonable probability". This would anticipate that no further medical diagnostic or therapeutic treatment is reasonably anticipated to result in a measurable change in the patient's complaints, function, or medical impairment. The AMA Guides qualify that the degree of impairment is not likely to change by more than $3 \%$ within the next year. Similarly, the concept of employability is also considered in MMI determination with the understanding that employability is not expected to change with further active medical treatment or surgical intervention. However, many states, agencies, and jurisdictions have additional and specific criteria used to define and designate maximum medical improvement. The accurate determination of MMI is in the best interest of the patient, physician, and insurer. The physician must be certain that the determination of maximum medical improvement is consistent with acceptable medical standards and principles and the accepted treatments or guidelines if available.

\section{Work Capacity}

Work capacity is a primary issue in work-related injuries. In evaluating work capacity, the Americans with Disabilities Act is taken into consideration. These are opinions that are formed by evaluation of the patient's report, clinical condition, and measurements of functional performance. 
Functional capacity evaluations or performance assessments may provide accurate information to determine the ability or disability of a person if the assessment is valid and reliable and is performed in relation to the individual's job. However, extreme caution should be exercised in this area, as reliability measures such as tests of consistency are good but imperfect indicators of the patient's efforts. Since there are numerous methodologies available in assessing functional performance, there are some protocols, which are structured and incorporate reliability measures, which are more beneficial than others. In arriving at work capacity rating, the physician must utilize the entire gamut of clinical skills and judgments and estimate the work capacities as carefully as possible, including the number of hours of work per day, based on the endurance and tolerance for sitting, standing, and walking. Estimates of lifting and carrying capabilities also should be noted with specific frequencies. Guidelines should be provided with regards to lifting, sitting, standing, walking, simple grasping, pushing and pulling of leg controls, bending/stooping, squatting/crouching, crawling, kneeling, and reaching. In addition, the impact of the condition on activities such as hearing, seeing, speaking, balancing, and restriction of activities involving unprotected heights, being around moving machinery, exposure to marked changes in temperature and humidity, driving automatic equipment, exposure to dust, fumes and gases, and exposure to vibration. Specific limitations beyond these should be delineated. These capacities should be compared with the functional requirements of the job, if available from job descriptions or direct observations. Customarily, these work capacity assessments are expressed in terms of an eight-hour workday. "Rarely" equals $0 \%$ to $5 \%$ of the time, "occasionally" equals $6 \%$ to $33 \%$, "frequently" equals $34 \%$ to $66 \%$, and "continuously" equals $67 \%$ to $100 \%$. The Dictionary to Occupational Titles from the United States Department of Labor provides categories and demands (primarily of lifting requirements), classified into categories of sedentary, light, moderate, heavy, and very heavy (21).

\section{Assignment of Impairment}

It is the responsibility of the physician to estimate the extent of the patients primary impairment or impairing condition; that is, the condition that is of most concern to the patient. The rating should be based on current findings and evidence. An impairing condition could involve several organ systems. However, the effect on one organ system alone may totally count for the negative effects on activities of daily living. If the effects on different organ systems are felt to separately contribute to impairment, the estimates of impairment should be combined. The AMA Guides (4) state:

- An impairment value that falls between those appearing in a table or figure of the Guides may be adjusted or interpolated to be proportional to the interval of the table of figure involved, unless other directions are given.

- Two measurements made by the same examiner are to lie within $10 \%$ of each other.

- Measurements should be consistent between trained observers and on separate occasions.

- In general, range of motion measurements are rounded to the nearest $10 \%$.

The final estimate may be rounded to the nearer of the two nearest values.

- In general, the impairment percent shown in the chapters that consider the various organ systems make allowance for the pain that may accompany the impairing condition.

- An addition of small percentage (1\% to $3 \%$ ) may be combined with any other impairment percent by means of the combined values chart if the effects of treatment prevent measurement of impairment, even though the previous state of normal good health is not regained.

- Pharmaceuticals themselves may lead to impairments. In such an instance, the physician should use the appropriate parts of the Guides to evaluate the impairment related to the pharmaceuticals.

- It must be emphasized and clearly understood that impairment percentages derived according to the Guides criteria should not be used to make direct financial awards or direct estimates of disabilities.

\section{Combining Versus Adding}

Combining is a mathematical process to prevent an estimate of impairment greater than $100 \%$. In combination each subsequent medical impairment is factored by the degree of the whole part of person remaining to be impaired (4). To illustrate the purpose and effects of combining versus adding, consider an example of an individual who has a $30 \%$ whole person impairment rating. However, there is another injury resulting in $20 \%$ whole person impairment rating. This additional $20 \%$ impairment rating is multiplied by half of the individual remaining (100\% minus $50 \%$ for the first rating) which is $14 \%$. The final impairment 
rating is the initial $30 \%$ and an additional $10 \%$ for a total of $44 \%$.

\section{SAMPLE IMPAIRMENT RATING}

In evaluation of the impairment of the spine using the AMA Guides, there are two methods for evaluating impairment (4). The injury model is always the first to be used. The range of motion model is to be used only if there is difficulty in placing the patient into a category or if there is disagreement between two physicians about which category to place a patient. However, the rating still comes from the injury model, not from the range of motion model.

\section{Salient Aspects}

A physician performing impairment evaluation should keep in mind the following in evaluation of impairment of the spine:

Evaluate the results of the injury but not the treatment.

- Use objective findings only.

Use the injury model for determining the final impairment.

- Define if the patient had a significant injury and if the patient had radiculopathy.
The injury model is divided into eight categories for each of the three areas of the spine: lumbosacral, thoracolumbar, and cervicothoracic. Lumbosacral spine impairments are described in Table 3.

\section{Differentiators}

Multiple differentiators utilized in arriving at a spinal impairment are as follows:

1. Guarding or spasm (dysmetria); non-verifiable root pain

2. Loss of reflexes

3. Decreased circumference, atrophy

4. Electrodiagnostic evidence

5. Loss of motion segment integrity

6. Loss of bowel or bladder function

7. Bladder studies

\section{Samples}

Category 1: A 34-year old white male with history of back strain, severe symptoms, but no objective findings $\rightarrow$ Category $1=0 \%$ impairment

Category 2: A 34-year old white male with history of back strain, severe symptoms with objective findings of spasm and non-verifiable root pain $\rightarrow$

Table 3. Lumbosacral spine impairment categories as per AMA Guides

\begin{tabular}{llc}
\hline Category & Description & $\begin{array}{c}\text { \% impairment of the } \\
\text { Whole Person }\end{array}$ \\
\hline I & Complaints or symptoms. No objective signs & 0 \\
II & Minor impairment: clinical signs of lumbar injury are present & 5 \\
III & Radiculopathy & 10 \\
IV & Loss of Motion Segment Integrity & 20 \\
V & Radiculopathy and loss of motion segment integrity & 25 \\
VI & Cauda equina-like syndrome without bowel or bladder & 40 \\
VII & impairment & 60 \\
VIII & Cauda equina syndrome with bowel or bladder impairment & 75 \\
\hline Adapted and & modified from Ref 4. &
\end{tabular}


Category $2=5 \%$ impairment

Category 3: A 34-year old white male with history of back strain, severe symptoms, with back injury and radiculopathy $\rightarrow$ Category $3=10 \%$ impairment

Radiculopathy: The diagnosis of radiculopathy is based on:

1. Positive straight leg raising test

2. Loss of reflex

3. Segmental weakness

4. Atrophy

5. Numbness in anatomic distribution

6. MRI (must correlate with other findings, though MRI is not necessary)

7. EMG (must have findings of radiculopathy, though is not necessary)

The same question always arises: what happens if the patient improves, deteriorates, undergoes surgery, or returns to work? With Category 3 as an example, the following scenarios are extrapolated:

1. The patient gets well without any treatment; the impairment is $10 \%$.

2. The patient gets well with conservative treatment; the impairment is $10 \%$.

3. The patient gets well with surgery; the impairment is $10 \%$.

4. Patient gets worse after surgery; the impairment is $10 \%$.

5. The patient does not get well with or without surgery; the impairment is $10 \%$.

6. The patient says the symptoms are recurring; the impairment is $10 \%$.

7. It changes from unilateral to bilateral; the impairment is $10 \%$.

8. Involves another level in the lumbar spine; the impairment is $10 \%$.

9. The patient undergoes fusion; the impairment is $10 \%$.

10. Fusion worsens his pain; the impairment is $10 \%$.

11. The patient had fusion removed; the impairment is $10 \%$.

Thus, a patient can be given impairment rating as soon as he or she reaches maximum medical improvement and as soon as the radiculopathy is definite in this case. Ironically, impairment remains the same with or without treatment, with or without improvement, and with or without deterioration.

In this age of accountability, either impairment evaluation or disability analysis should be held to the same high standards of medicine. These reports should be written competently in an ethical and economically-accessible manner. However, in the real world, this is an extremely difficult venture, as there are no established standards, training parameters, or board certifications by any of primary boards approved by American Board of Medical Specialties (ABMS). Medicine is an art, and there are very few diagnoses or opinions that can be rendered with $100 \%$ certainty. In medicine physicians are able to express the strength of their beliefs in hundreds of ways, rarely describing a situation as true or false, black or white. However, law and disability issues are technical and not only require but mandate the use of language that is definitive and clear. If ambiguous words or phrases are used, then the issue remains "unclear or gray," and another medical opinion will need to be obtained, perhaps from a different doctor. Physicians, while writing medical/legal reports, frequently feel pressure from attorneys, insurance adjustors, employers, and patients to reflect their own interests. The results of this pressure depend on whether the physician writing the report is an independent medical evaluator or a treating physician. Consequently, the source of pressure also varies. The best advice to a physician is to tell the truth and not yield to pressure or sale out to any of the interests. Once again, this will be an extremely difficult situation, specifically for independent medical evaluators or disability analysts whose practice depends on these referrals. Essentially, the report should try to adhere to the 3 R's (4):

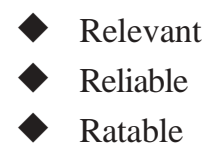

A report that meets all $3 \mathrm{R}$ 's is a credible report, providing a description of the history and physical examination findings. The report should also be relevant, clear, and concise, and confined to the specific issues in question. Finally, a ratable report uses the correct medical/legal terminology in order to describe levels of disability and physical impairment according to legal standards.

An impairment report should consist some or all of the following items based on type and extent of evaluation:

1. History of present illness: 


\section{History of medical condition \\ Present complaints \\ Present status}

2. Past, family, and social history

Previous pain history

Previous injury history

Previous medical history

Family history

Social history

Occupational history

Disability status of work activities and work duties

3. Review of systems

4. Evaluation
Physical
Functional
Psychological
Symptom magnification

5. Decision Making

Diagnostic studies
Review of medical records
Diagnostic impression
Laboratory tests
6. Impairment evaluation
- Causal relationship
Maximum medical improvement
Impairment rating
Apportionment
7. Restrictions
$\checkmark \quad$ Physical
$\checkmark \quad$ Mental
8. Conclusion

\section{CONTROVERSIES}

Controversies in impairment evaluation range from creditability of evaluation, pain and impairment; symptom magnification; and malingering or deception. The definition of independent medical evaluation, pitfalls of evaluation by an independent physician, and pitfalls of evaluation by a treating physician have been described earlier. While there are advantages and disadvantages to independent physi-

\section{Table 4. Pitfalls with conventional evaluation of low back pain}

\section{"Specific anatomic etiology is clearly and objectively identified in only $10 \%$ to $20 \%$}

1. Radiographic "abnormalities" are frequently clinically irrelevant.

2. True sciatica occurs in only 1 to $2 \%$ of the patients.

3. No universal criteria are established for scoring the presence, absence, or importance of particular signs.

4. Quantification of the degree of disability and the association to treatment outcomes is difficult.

5. Interpretation of biomedical findings relies on "clinical judgments," "physician's experience," and "quasistandardized criteria."

6. Routine clinical assessment is frequently subjective and unreliable.

7. Physical examination and diagnostic findings are subjective

8. The discriminative power of common objective signs has been questioned.

9. Reliance on general "clinical impression" to detect gross psychological disturbances is "hopelessly inaccurate."

10. It is usually not possible to make a precise diagnosis or identify anatomic origin of the pain by routine clinical assessment.

Adapted and modified from Waddell and colleagues (25) 
cians and treating physicians, most often independent clinicians come up with "no objective findings" in patients with back or neck pain. Hendler et al (22), to whom a number of suspected psychosomatic cases have been referred, found organic origin of the pain in $98 \%$ of cases. Subsequently, Hendler and Kolodny (23) estimated that the incidence of psychogenic pain is only one in 3,000 patients. It also has been shown repeatedly that clinical features and imaging or neurophysiologic studies do not permit the accurate diagnosis of the causation of spinal pain in the majority of the patient in the absence of disc herniation and neurological deficit (24). Further, it has been shown that overall rate of inaccurate or incomplete diagnosis in patients referred to pain treatment centers to range from $40 \%$ to $67 \%$. Chronic low back pain is a diagnostic dilemma in $85 \%$ of the patients, even in experienced hands with all the available technology (22-24). Table 4. shows pitfalls with conventional evaluation of low back pain as described by Waddell and colleagues (25). As described earlier, the credibility of professional evaluators is constantly questioned.

Controversy surrounds pain and impairment. Even though chronic pain is a major health problem in society, and the medical, social, and economic consequences are enormous, numerous difficulties when dealing with pain are based in part on the following characteristics and perceptions:

1. Pain is a multi-faceted concept. Pain is not only due to pathophysiologic factors but also includes cognitive, behavioral, environmental, ethnic and cultural variables.

2. Pain is subjective and cannot be validated or measured objectively.

3. Impairment due to pain has not been well-defined.

Chapter 15 of the AMA Guides provides a discussion of pain and describes a method to characterize chronic pain but does not provide any impairment percentages (4). Rather it refers the physician to the various other organ systems provided in the Guides.

Basically, the impairment percents of the various organ systems include allowances for the pain that may occur with those impairments. Chronic pain is subjective and cannot be measured or detected in any reliable manner; pain evaluation requires knowledge and understanding of a multi-faceted, biopsychosocial model. Pain and impairment estimates are based on the physician's training, experience, skill, thoroughness, and representative blend of the science of medicine. Pain should be evaluated by physicians who are conversant with the disorder.
Pain has been defined and classified in a number of ways. Pain has been described as:

1. Nociceptive or somatic pain

2. Neurogenic or central pain

3. Psychogenic or physical pain

4. Primary or secondary pain

5. Acute, recurrent, persistent, or chronic pain

In many cases, chronic pain is understood as persistent pain that is not amenable to routine pain control methods. However, most physicians performing impairment evaluations; to a great extent, others confuse persistent pain with chronic pain syndrome. Thus, two major and controversial terms in today's pain medicine are "chronic pain," also known as persistent pain; and a second category known as "chronic pain syndrome," which is a separate and distinct condition $(4,5)$. Chronic pain syndrome is associated with major psychological and behavioral problems, with or without physical problems. Recurrent pain represents the nidus of chronic pain syndrome. While chronic pain may be associated with psychological problems such as depression, generalized anxiety disorder, and some behavioral problems, chronic pain syndrome, in contrast, is a malevolent and destructive force $(4,5,24)$. Chronic pain syndrome is a self-sustaining, self-reinforcing, and selfregenerating process, with markedly enhanced perception and with maladaptive and grossly disproportional painrelated behavior. However, relevant literature shows that chronic pain syndrome is not a common problem (22-24). Chronic pain syndrome is differentiated as per AMA Guides, with the presence of at least four of the eight characteristics, which are described as the eight d's (4):

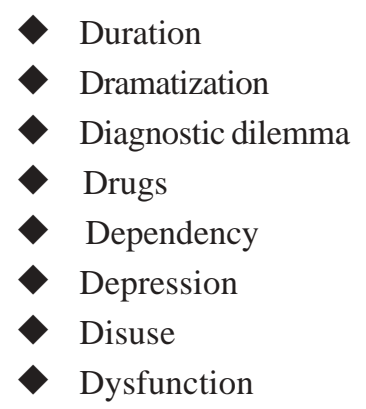

For the patient's pain to be evaluated and considered an impairment, it must be persistent, chronic, stable, and unlikely to change in the future despite therapy by definition. Impairment is based on the decreased ability to carry out daily activities; an individual who complains of constant pain but who has no objectively validated limitations in daily activities has no impairment. 
Symptom magnification is the most abused and misused diagnosis and terminology in the today's impairment evaluation and disability medicine. Many so-called independent evaluators neither know nor understand the symptom magnification syndrome. Symptom magnification syndrome (SMS) is defined as, "a self-destructive, sociallyreinforced behavioral response pattern consisting of reports or displace of symptoms, which function to control the life of circumstances of the sufferer" by Matheson (27), who coined the term. The definition of symptom magnification syndrome, encompasses these important aspects:

1. It may be conscious or unconscious.

2. It is self-destructing.
3. It is a pattern of behavior which is learned and maintained through social reinforcement.

4. It is composed of reports and/or displays of symptoms.

5. The effect of the behavior response pattern is to control the life circumstances of the sufferer.

Symptom magnification syndrome has its roots in the "sick role," first published by Parsons (28), who reported that the sick role is conferred on the individual who is ill and actively involved in treatment. The patient in the sick role is allowed to temporarily escape from other responsibilities.

\section{Table 5. Common terminology in impairment evaluation}

Impairment: A deviation from a normal in a body part or organ system and its functioning. It is an alteration of individual's health status.

Permanent Impairment: One that has become static or stabilized during a period of time sufficient to allow optimal tissue repair, and one that is unlikely to change in spite of further medical or surgical therapy. A permanent impairment is considered unlikely to change substantially and by more than $3 \%$ in the next year with or without medical treatment.

Disability: Disability is a decrease in, or the loss or absence of, the capacity of an individual to meet personal, social, or occupational demands, or to meet statutory or regulatory requirements. It is the gap between what a person can do and what the person needs or wants to do. It is inability or altered ability to successfully accomplish a given task.

Permanent Disability: Occurs when the limiting loss or absence of capacity becomes static or well stabilized and is not likely to change in spite of continuing use of medical rehabilitative measures. A permanent disability is considered unlikely to change substantially and by more than $3 \%$ in the next year with or without medical treatment.

Causal Relationship: Causation means that a physical, chemical, or biological factor contributed to the occurrence of a medical condition.

Medical Determination: Alleged factor should have caused or contributed to impairment . Non-medical determination: Alleged factor caused or contributed to impairment.

Maximum Medical Improvement: MMI represents that point in time when, as the patient's medical condition has reached where the condition has stabilized or hit a plateau, no further material recovery or lasting improvement is expected or reasonably anticipated as a result of additional treatment based on reasonable probability. MMI is not to exclude a patient from further treatment, whether it's follow-up, maintenance or palliative care, and whether such treatment increases functional status or not.

Adapted from AMA Guides (4) 
The assessment process of symptom magnification is a prolonged and time-consuming, involving detection of various signs and symptoms. However, this is seldom performed in independent evaluations. Yet the diagnosis of symptom magnification is based on non-physiological symptoms and signs of Waddell et al $(29,30)$ alone. Nonphysiological signs of Waddell and coworkers are generally misunderstood and thus incorrectly applied, accusing the patient of unjustly committing fraud; while, in fact, the evaluating physician may be committing fraud (29-32).

The final assumption by many physicians performing socalled independent evaluations is that most patients, if not all, are malingering and deceptive. This actually works in a reverse manner with treating physicians, as they many times naively buy into bizarre symptomatology of pain and dysfunction. As Abraham Lincoln once said: "The simple truth and you won't have so much to remember". The simple truth will be beneficial to all parties; however, that is sometimes hard to come by.

\section{CONCLUSION}

Impairment evaluation is a complex process that is a distinct entity from medical evaluation and not familiarized during medical school or training. AMA Guides to the evaluation of permanent impairment provide the most commonly-used methodology in the United States. Definitions of common terms used in impairment evaluation, i.e. impairment, permanent impairment, disability, permanent disability, causal relationship and maximum medical improvement, are described in Table 5. An honest evaluation by a credible physician, with attention to facts and only objective findings, will be the simplest and the best in today's practice of interventional pain management. As Samuel Butler once said: "Any fool can tell the truth, but it requires a man of some sense to know how to lie." This may be literally applied to both an evaluator and intelligent manipulative patient.

\section{REFERENCES}

1. Giureje O, Von Korff M, Simon GE et al. Persistent painand well being: A World Health Organization Study in Primary Care. JAMA 1998;280:147-151.

2. Cousins MJ. Pain: The past, present, and future of anesthesiology? The E.A. Rovenstine Memorial Lecture. Anesthesiology 1999; 91:538-551.

3. Bonica JJ. Definitions and taxonomy of pain. In: Bonica JJ, Loessor JD, Chapman CR, Fordyce WE (eds). The management of pain, Second Edition, Philadelphia, Lea
\& Febiger, vol 1, 1990: PP18-27.

4. Guides to the evaluation of permanent impairment. Fourth Edition, Chicago. American Medical Association; 1993.

5. Merskey H, Bogduk N. Classification of chronic pain: Descriptions of chronic pain syndromes and definitions of pain terms. Second Edition. IASP Press, Seattle, 1994.

6. Leigh JP, Markowitz S, Fahs M et al. Occupational injury and illness in the United States. Estimates of costs, morbidity, and mortality. Arch Intern Med 1997; 157:1557-1568.

7. Greenwood JD. History of disability as a legal construct. In: Demeter SL, Andersson GBJ, Smith GM (eds). Disability Evaluation, St. Louis, Mosby; 1996: pp5-12.

8. Speiler E. Perpetuating risk. Workers' Compensation and the persistence of occupational injuries. Houston Law Review 1994; 3:119-264.

9. Social Security Amendments. PL 761, Title 1, Section 215(i), Par 3. Washington, DC; 1954.

10. International classification of impairments, disabilities, and handicaps. World Health Organization, Geneva, Switzerland; 1980.

11. Melvin JL, Nagi SZ. Factors in behavioral responses to impairments. Arch Phys Med Rehabil 1970; 51:552557.

12. Melvin JL. When is permanent permanent? Trial techniques: The medical issue. Columbus: Ohio Legal Center Institute.

13. Pain and disability - Clinical behavioral and public policy perspective. Osterweis M, Kleinman A, Mechanic D (eds). Committee on Pain, Disability and Chronic Illness Behavior. Washington, DC, National Academy Press.

14. Guides to the evaluation of permanent impairment. Third Edition. Chicago, American Medical Association, 1988.

15. McLellan JD. Overview of various disability systems in the United States. In: Demeter SL, Andersson GBJ, Smith GM (Eds). Disability Evaluation. St. Louis, Mosby; 1996: pp 20-30.

16. Sullivan MD, Loeser JD. The diagnosis of disability. Treating and rating disability in a pain clinic. Arch Intern Med 1992; 152:1829-1835.

17. Casey V. Industrial Comm'n of Ariz., 731 P2d 645 (Ariz. Ct. App. 1987).

18. Jefferson County School vs. Headrick, 734 P2d 659 (Colo. Ct. App. 1986).

19. Mountain Shadows Resort Hotel vs. Indu. Comm'n, 710 P2d 1066 (1985).

20. Patterson vs. Wellcraft Marine, 509 So. 2d 1195 (Fla $1^{\text {st }}$ Dist. Ct. 1987).

21. Dictionary of occupational titles. Fourth Edition. Us Department of Labor. Employment and Training Administration. Washington, US Government Printing Office, 1977 
22. Hendler NH, Bergson C, Morrison C. Overlooked physical diagnoses in chronic pain patients involved in litigation. Part 2. Psychosomatics 1996; 37:509-517.

23. Hendler NH, Kolodny AL. Using medication wisely in chronic pain. Patient Care 1992; May 15, 125.

24. Manchikanti L, Singh V, Bakhit CE et al. Interventional techniques in the management of chronic pain. Part 1.0. Pain Physician 2000; 3:7-42.

25. Waddell G, Turk DC. Clinical assessment of low back pain. In: Turk DC, Melzack R (eds). Handbook of pain assessment. First Edition. New York, The Guilford Press. 1992; pp15-36.

26. Corran TM, Farrell MJ, Helme RD et al. The classification of patients with chronic pain: Age as a contributing factor. Clin J Pain 1997; 13:207-214.

27. Matheson L. Symptom magnification syndrome structured interview. Rationale and procedure. J Оссир Rehab 1991; 1:43-55.
28. Parsons T. The social system (Chap X) New York: Free Press of Glencoe, 1951.

29. Waddell G, McCulloch JA, Kummel E et al. Nonorganic physical signs in low back pain. Spine 1980; 5:117-125.

30. Waddell G, Main CJ, Morris EW. Chronic low-back pain, psychologic distress, and illness behavior. Spine 1984; 8:209-213.

31. Maruta T, Goldman S, Chan CW et al. Waddell's nonorganic signs and Minnesota multiphasic personality inventory profiles in patients with chronic back pain. Spine 1997; 22:72-75.

32. Main CJ, Waddell G. Behavioral responses to examination. A reappraisal of the interpretation of “nonorganic signs.” Spine 1998; 23:2367-2371. 